\title{
Concise Synthesis of a Potential FLAP Inhibitor and Its Analogs through Late-Stage Alkene Dicarbofunctionalization
}

Shekhar KC, Roshan K. Dhungana, Vivek Aryal, and Ramesh Giri*

Department of Chemistry \& Chemical Biology, The University of New Mexico, Albuquerque, NM 87131, USA.

Table of Contents

NMR Spectra 


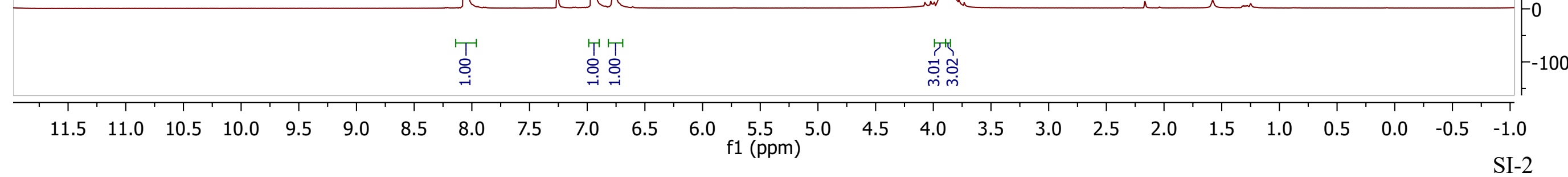


<smiles>COc1ccc(C(C)=O)c(Br)c1</smiles> 

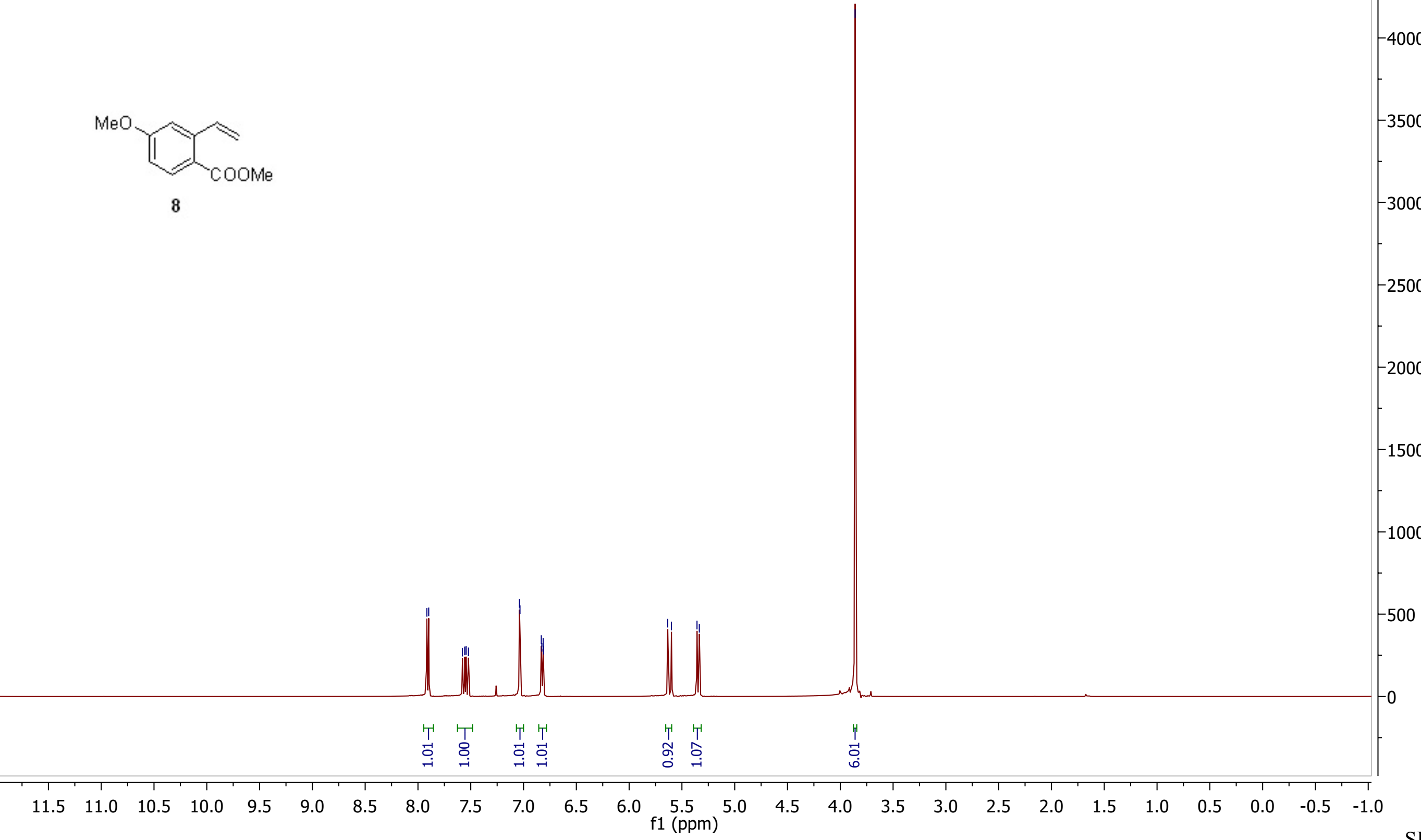


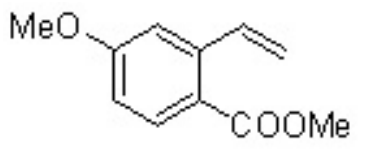



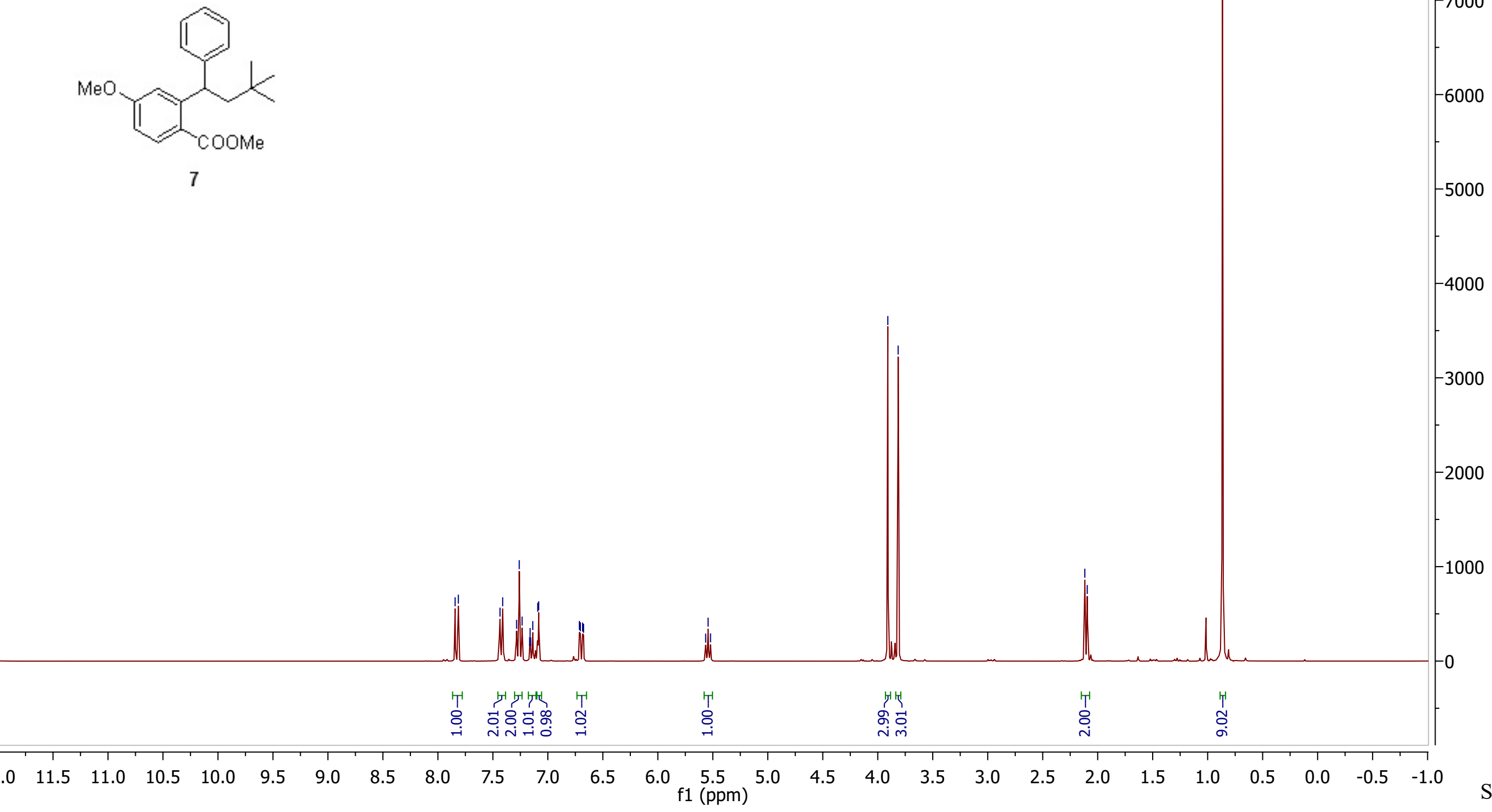


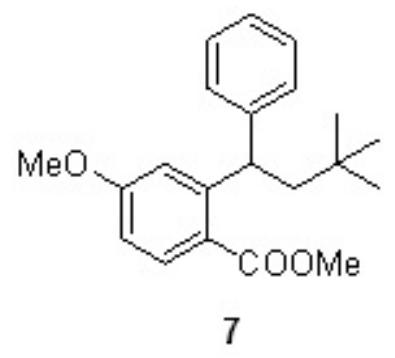




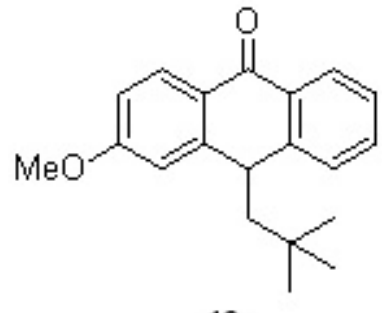

16000

12 


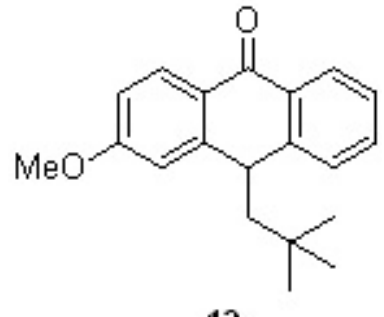



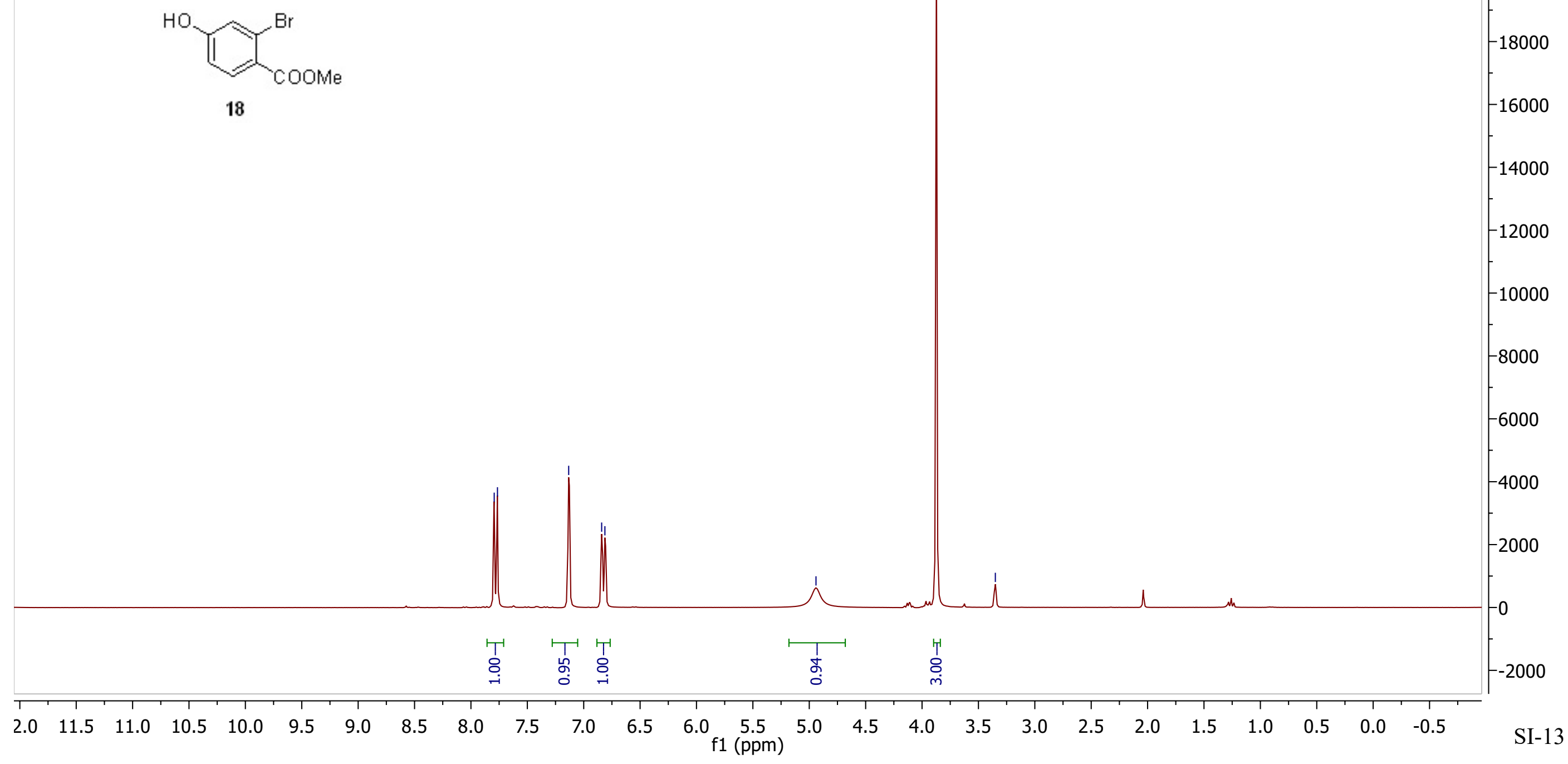


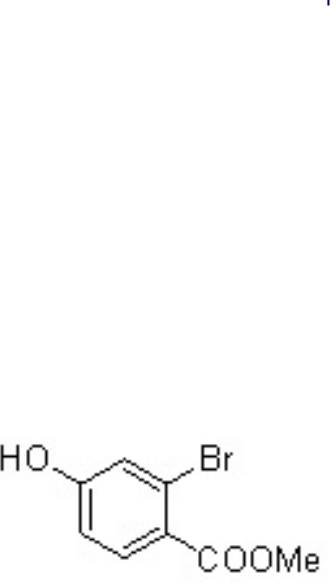

18

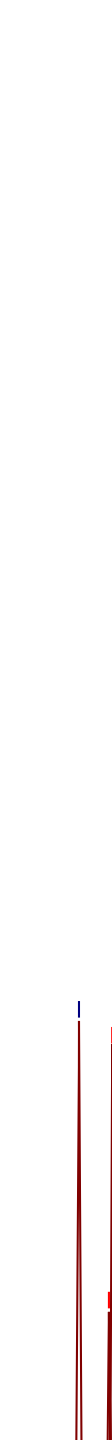




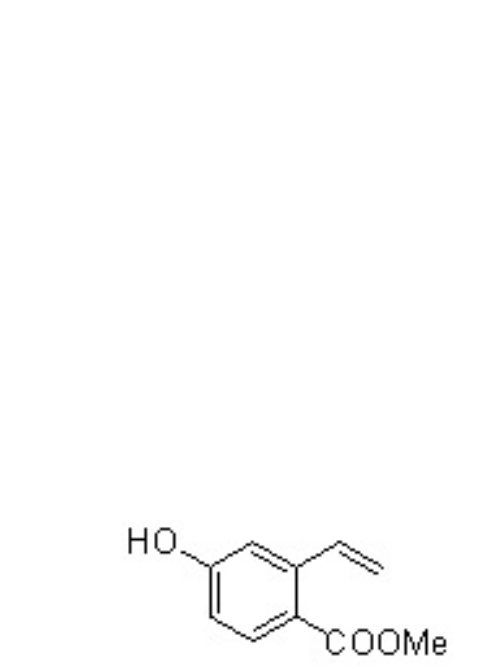

19

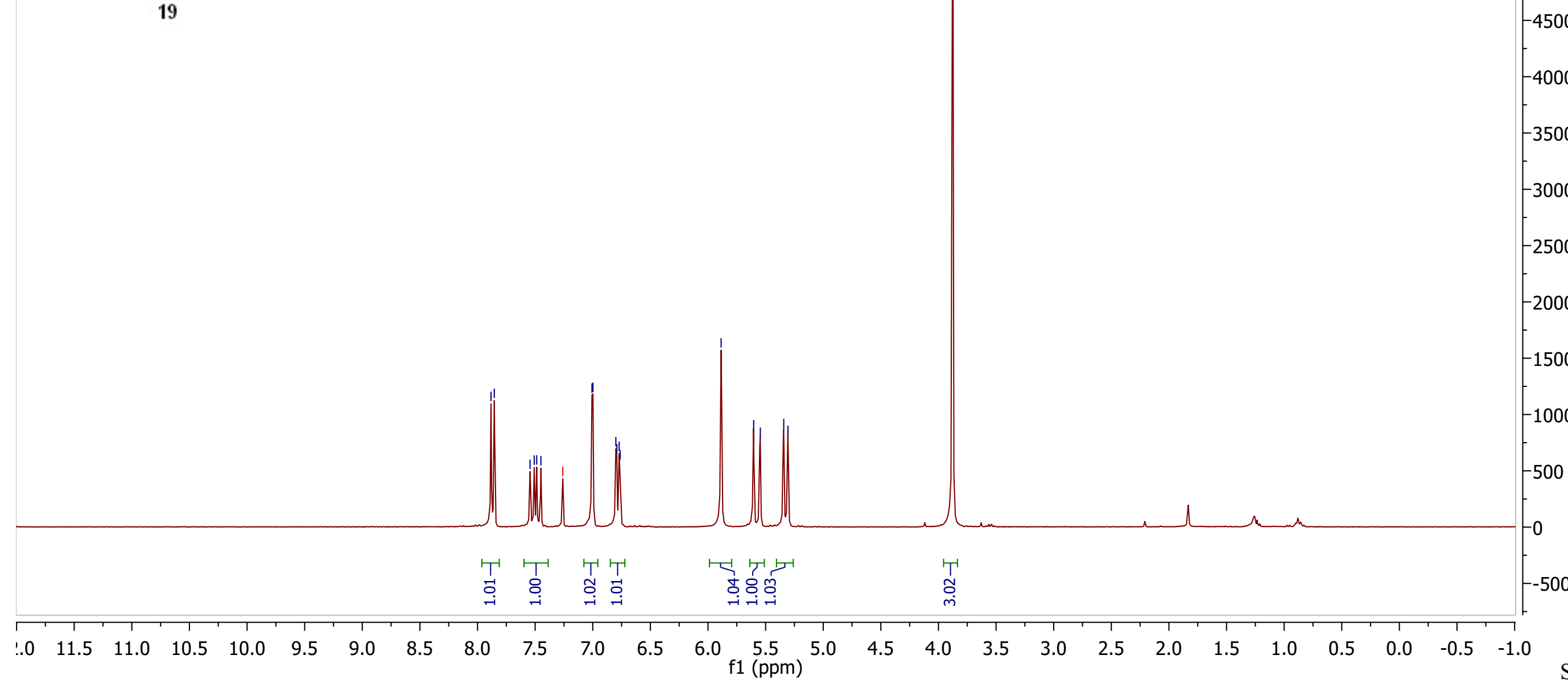




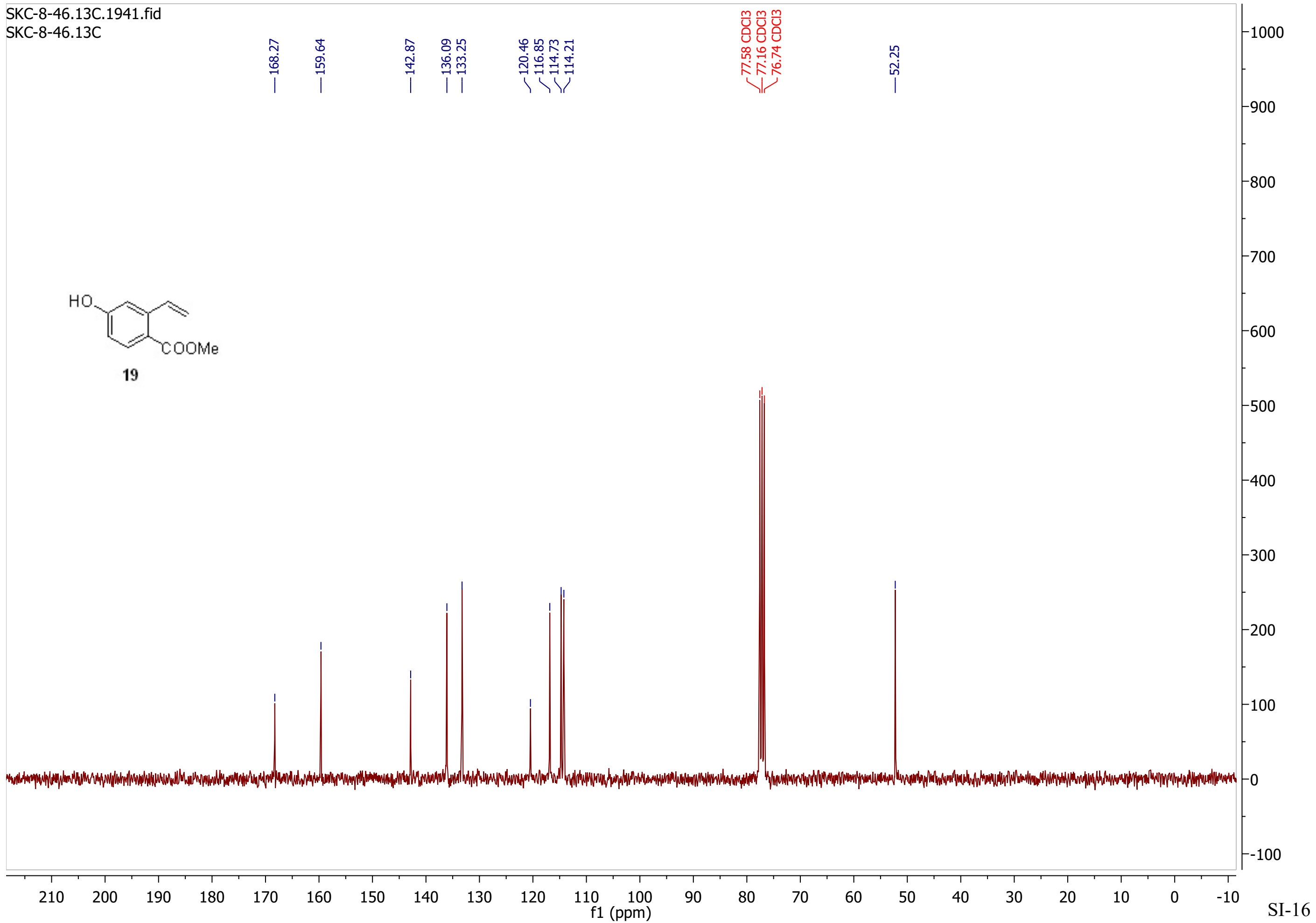




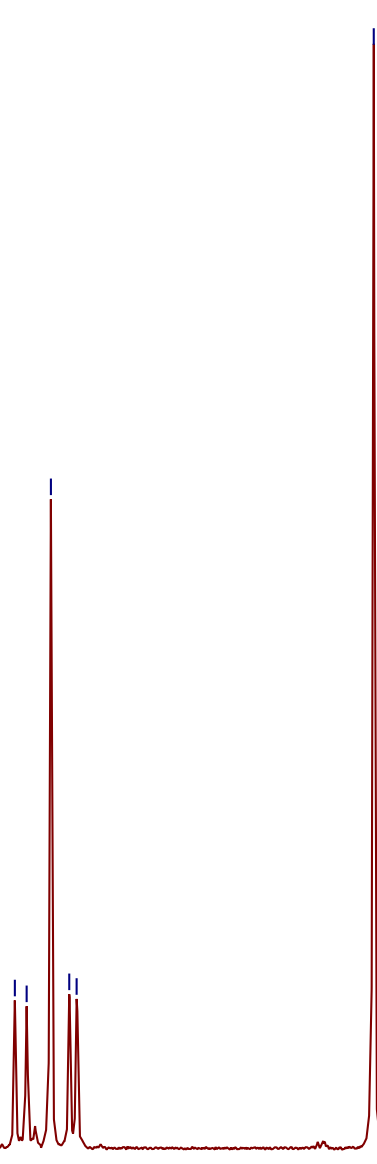




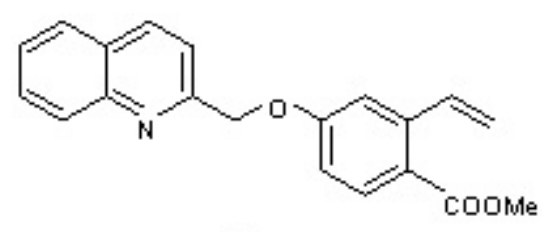

15

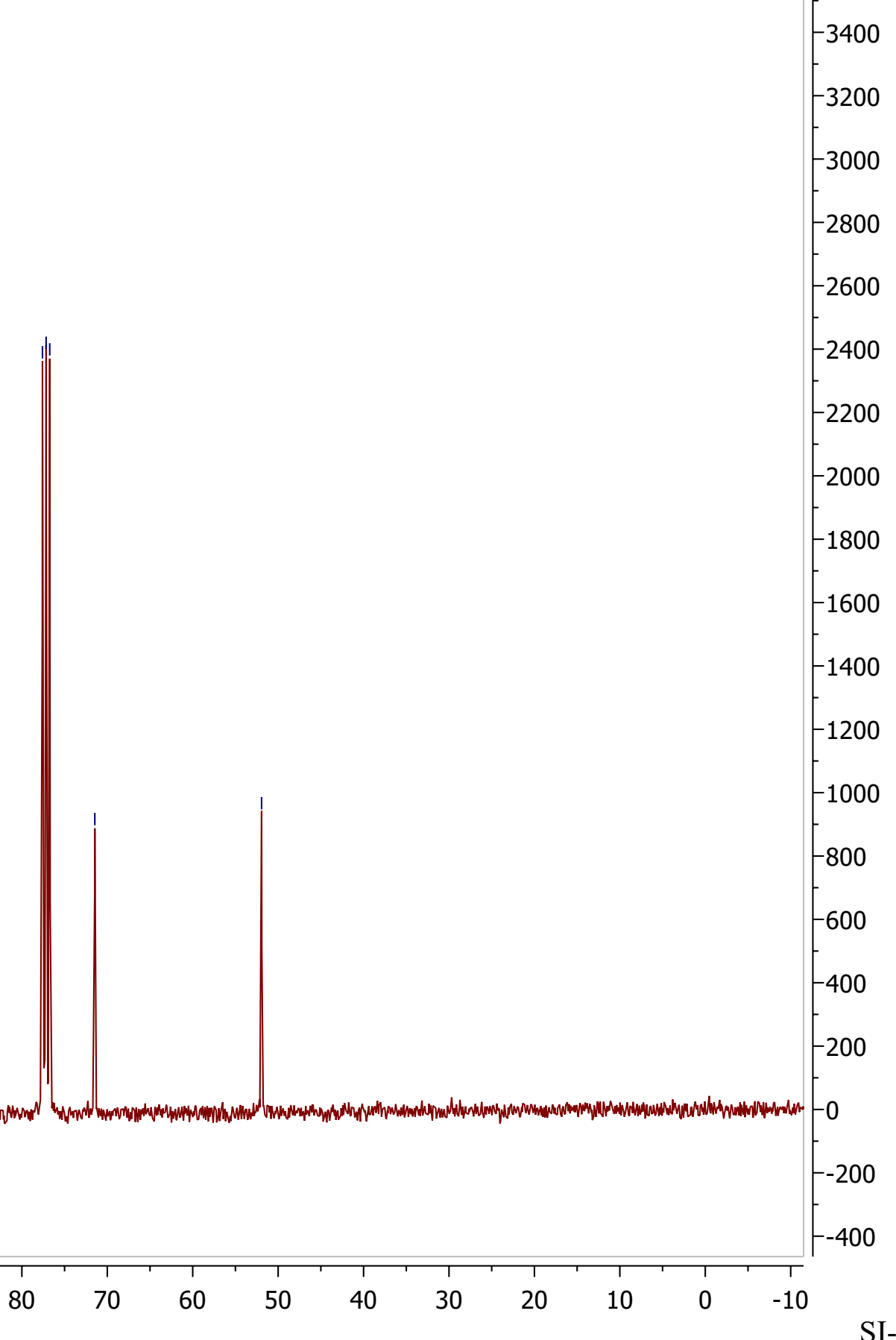




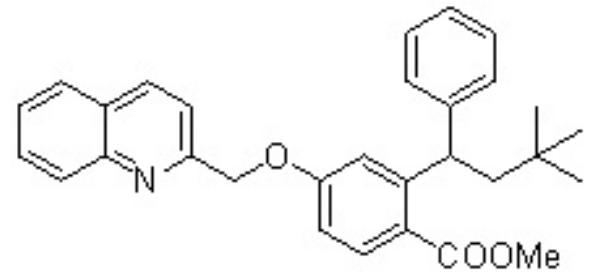

1

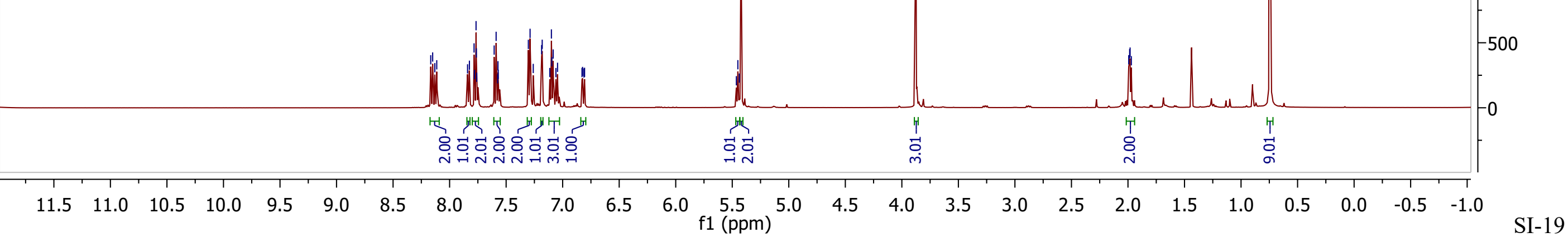




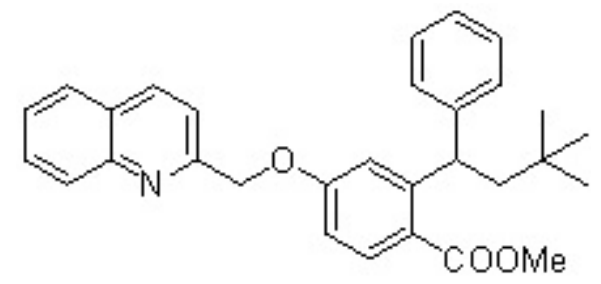

1

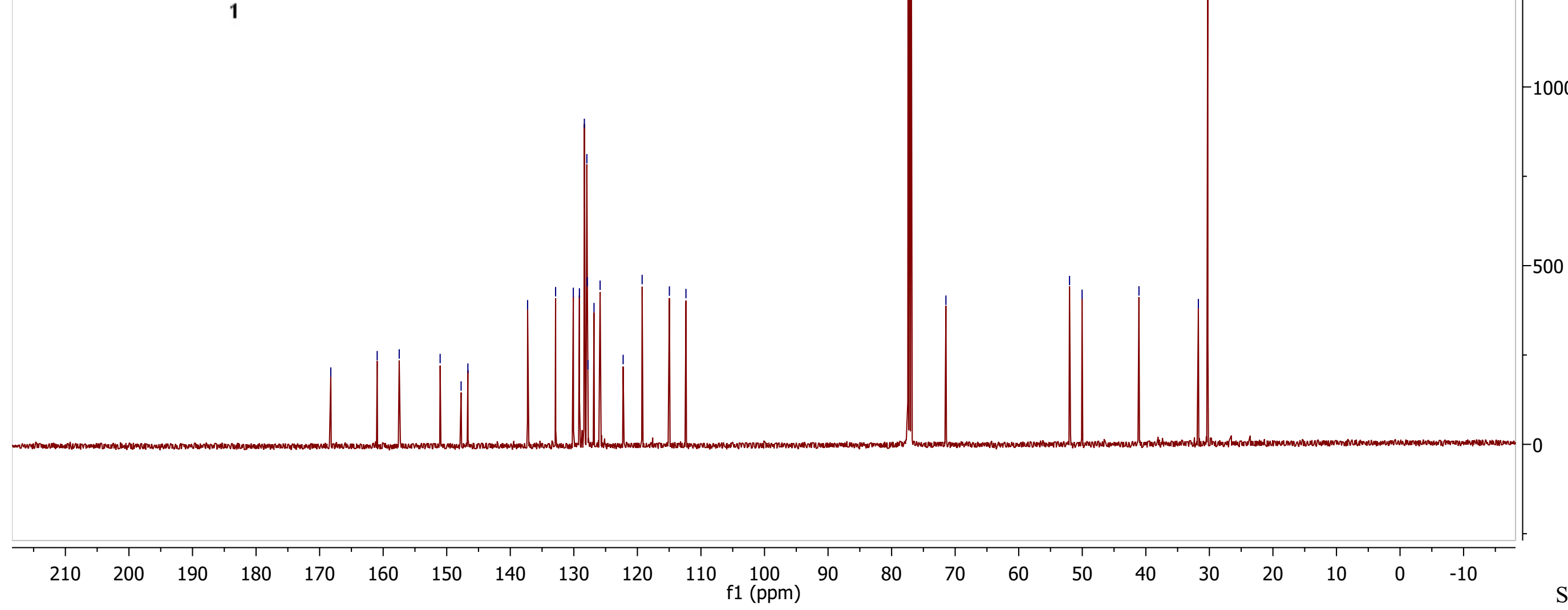




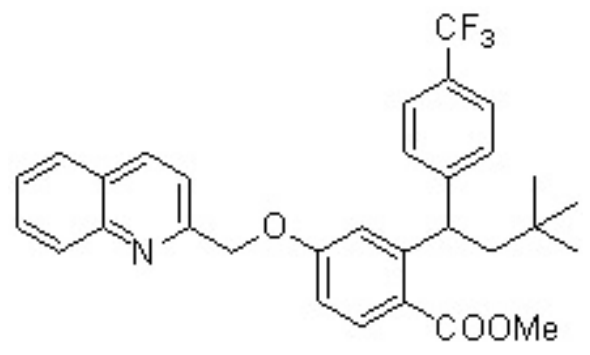

21

5000
-4500
-4000
-3500
-3000
-2500
-2000
-1500
-1000
-500
-0
-500
SI-




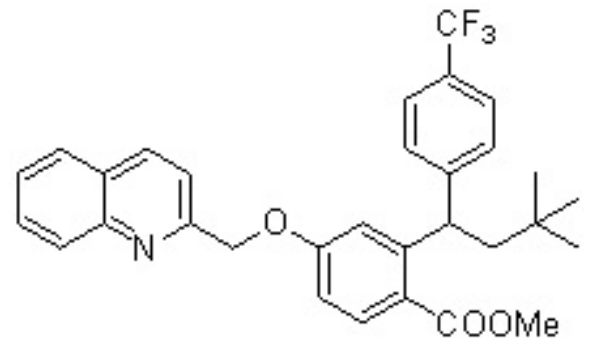




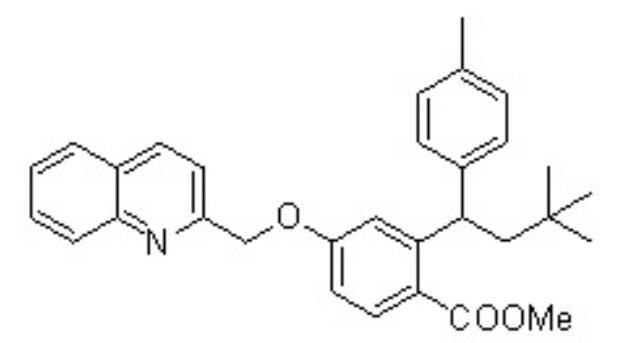

22 

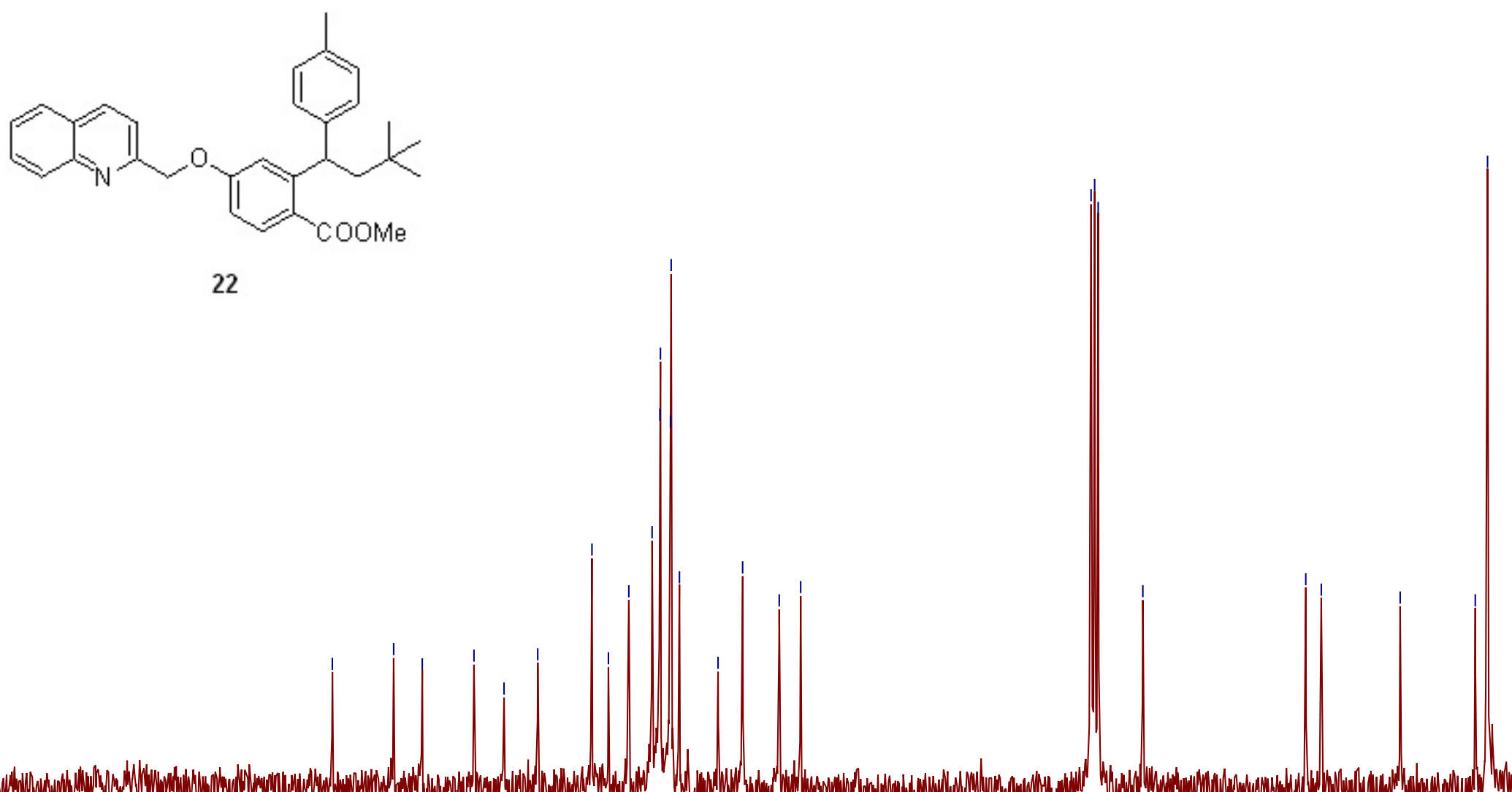


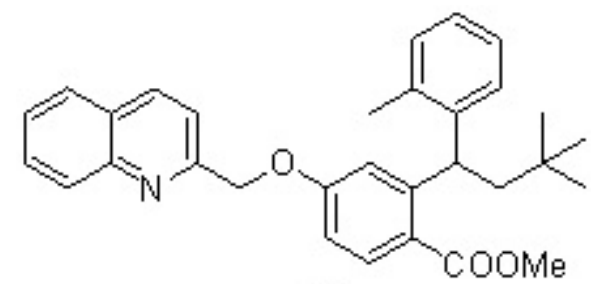

23

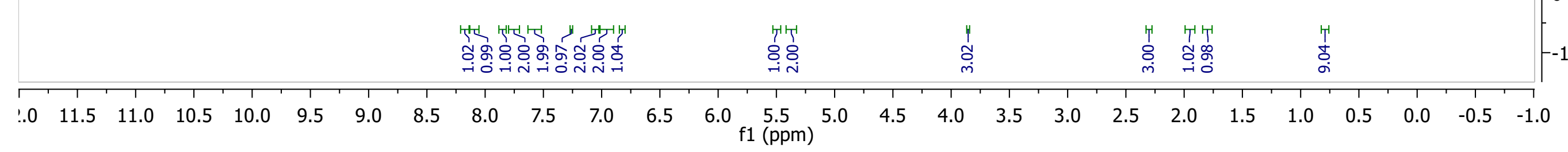




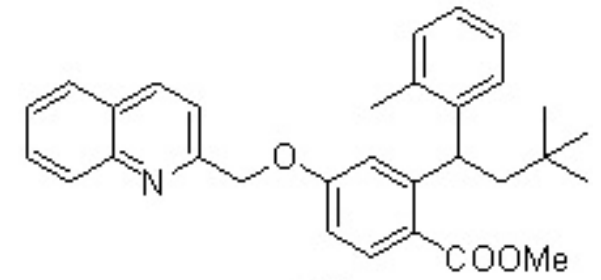

23

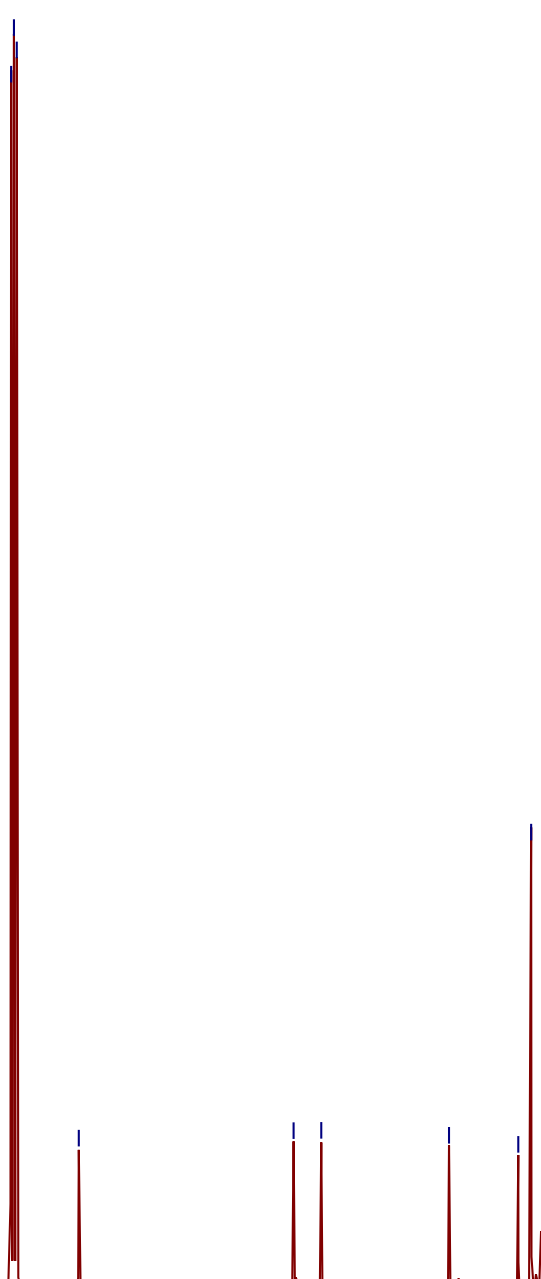




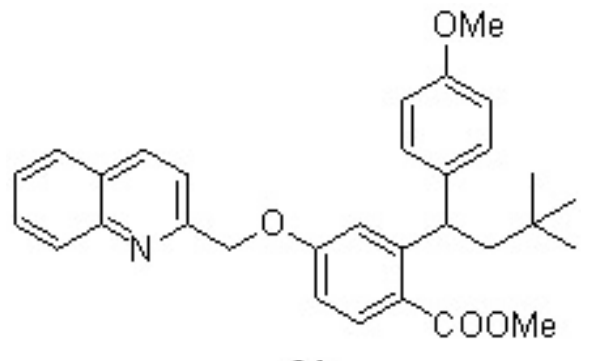

24

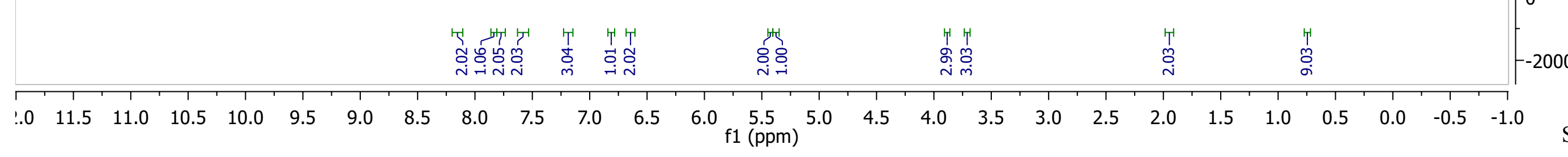




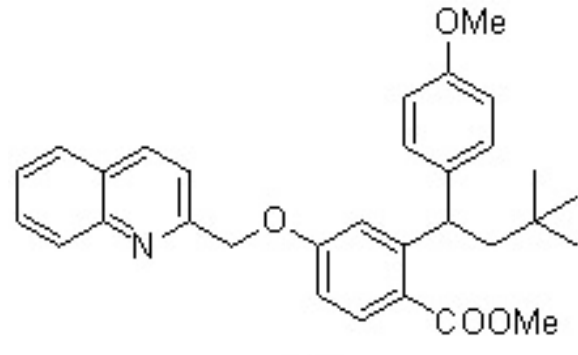




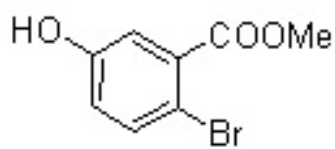

26 

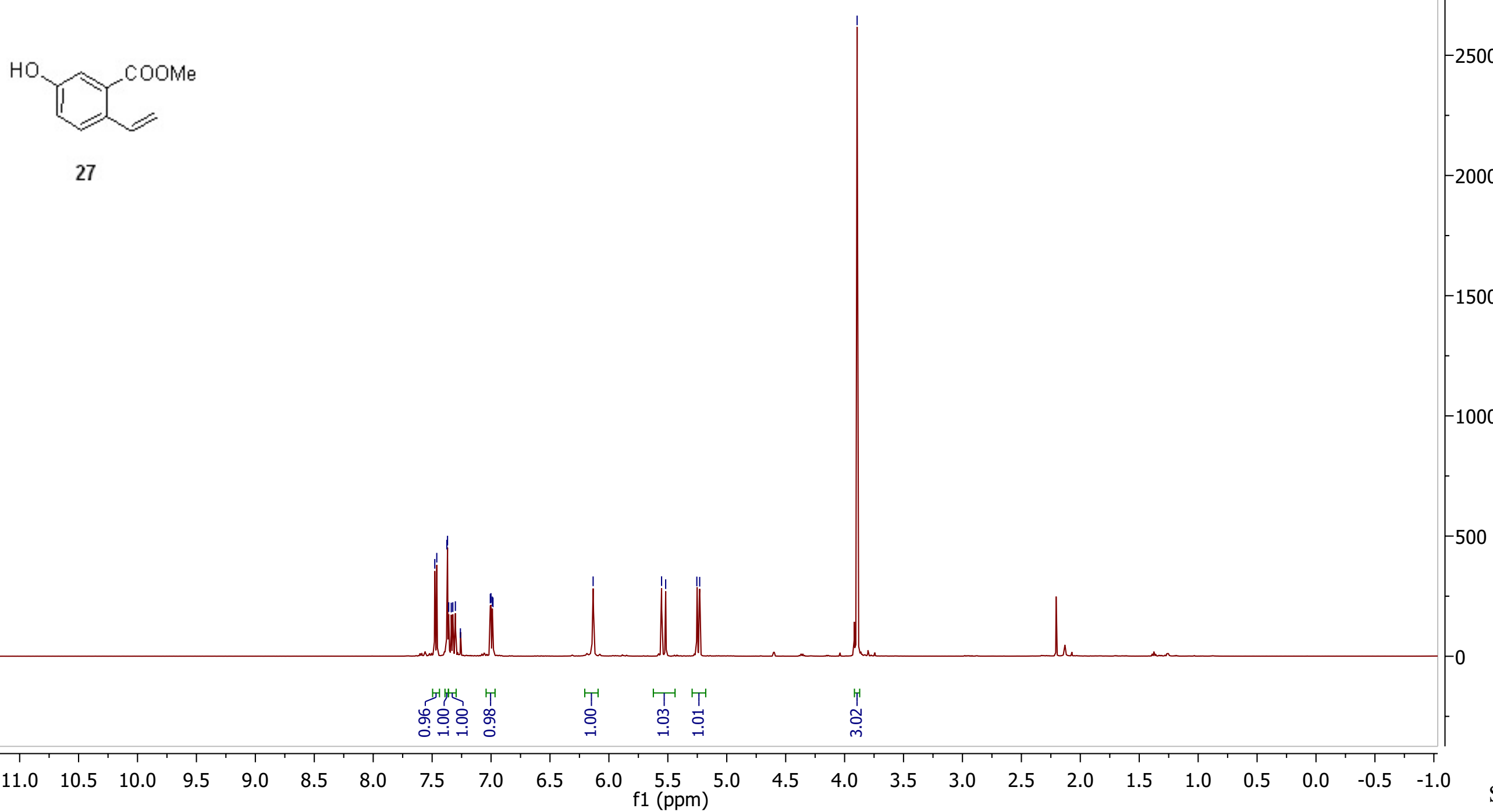


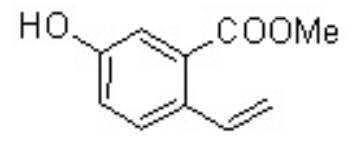



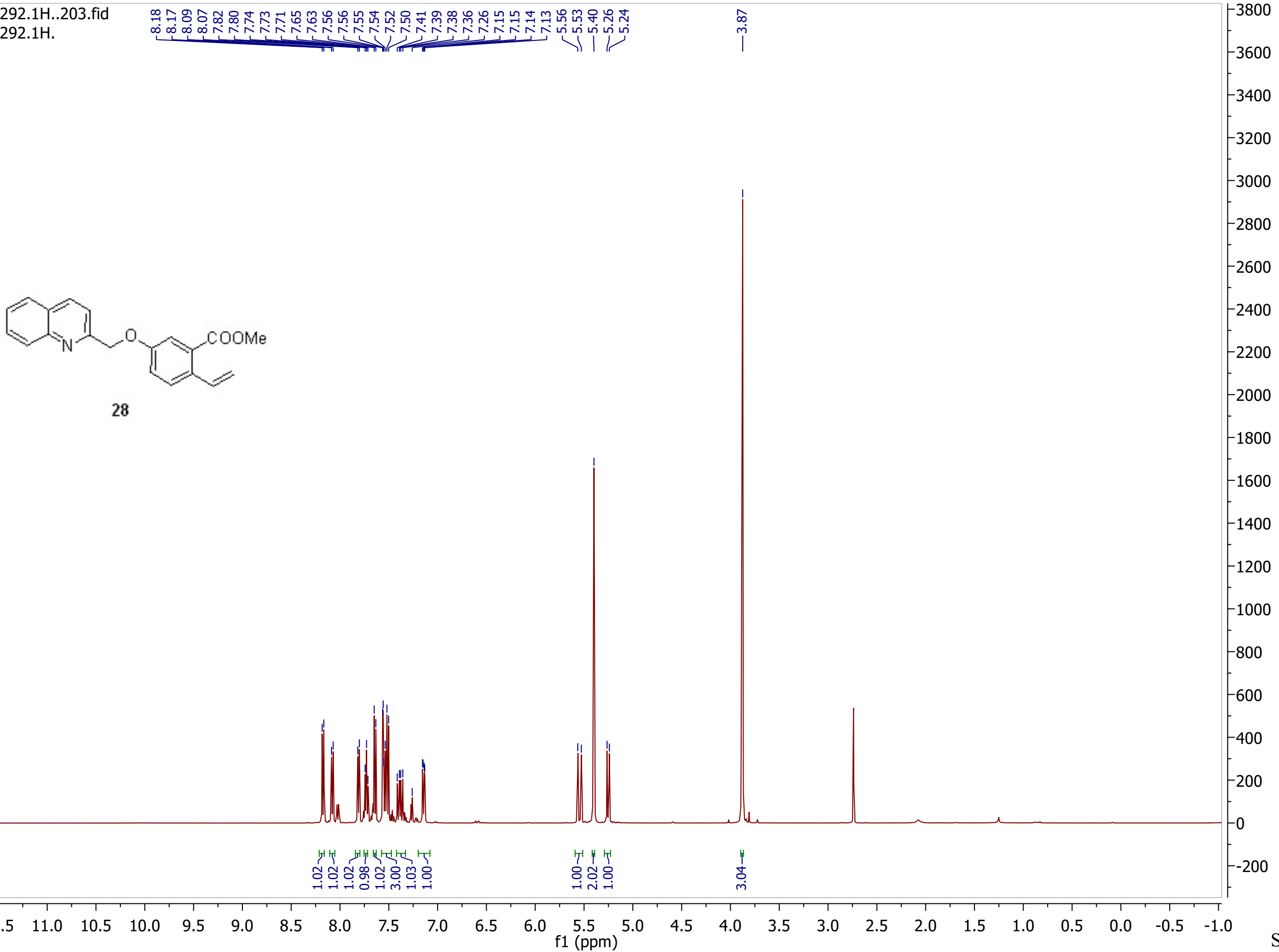

28 


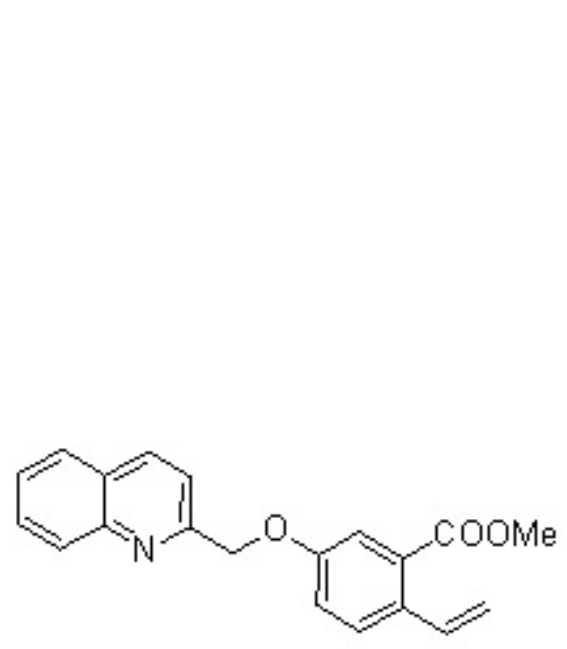

28

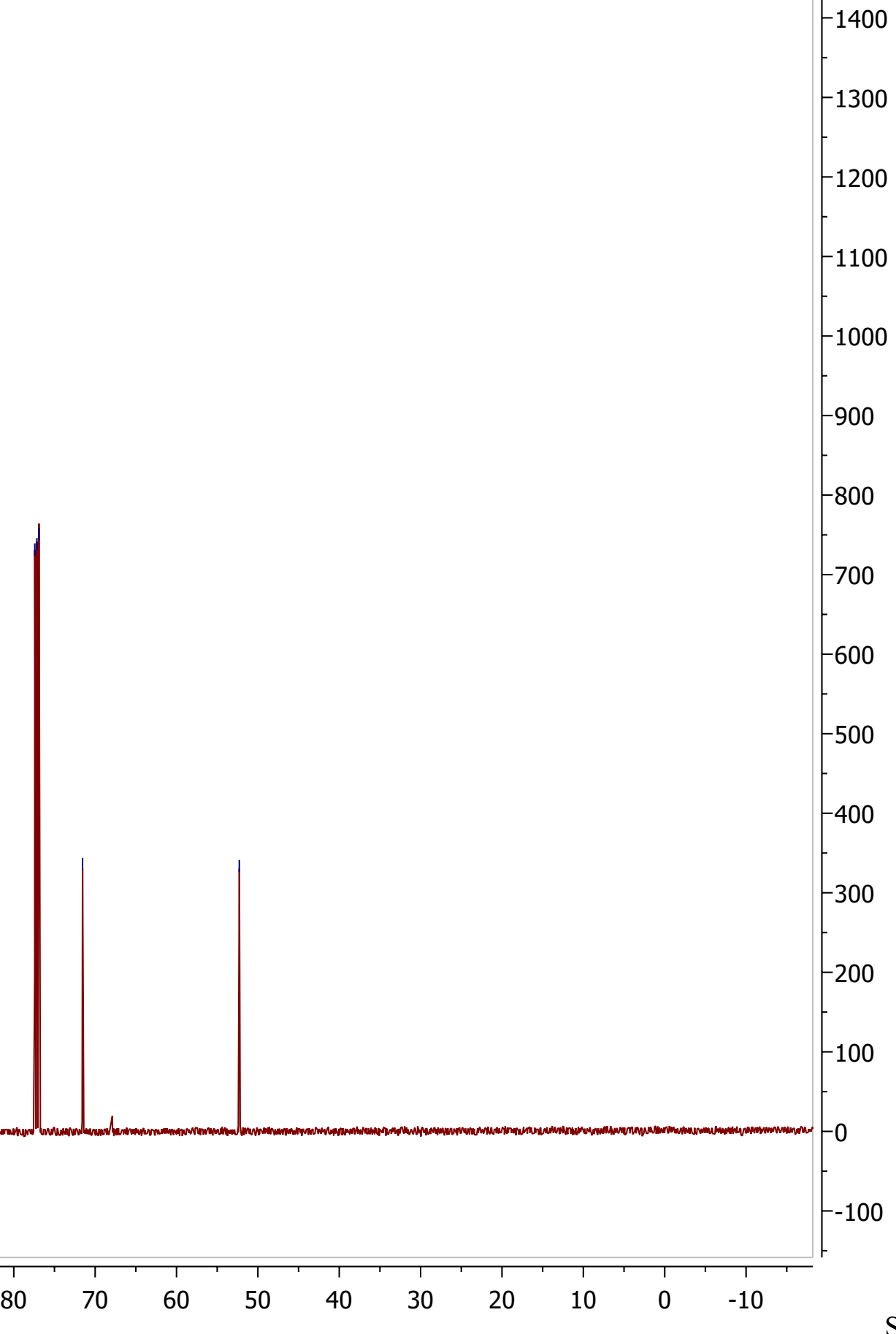


<smiles>CC(=O)c1cc(OCc2ccc3ccccc3n2)ccc1C(CC(C)(C)C)c1ccccc1</smiles>

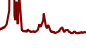


<smiles>CC(=O)c1cc(OCc2ccc3ccccc3n2)ccc1C(CC(C)(C)C)c1ccccc1</smiles> 


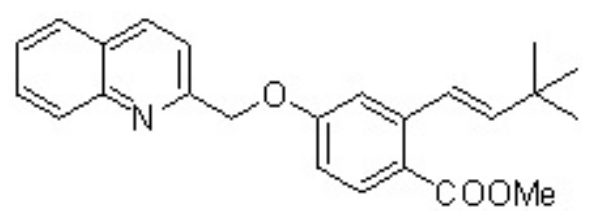



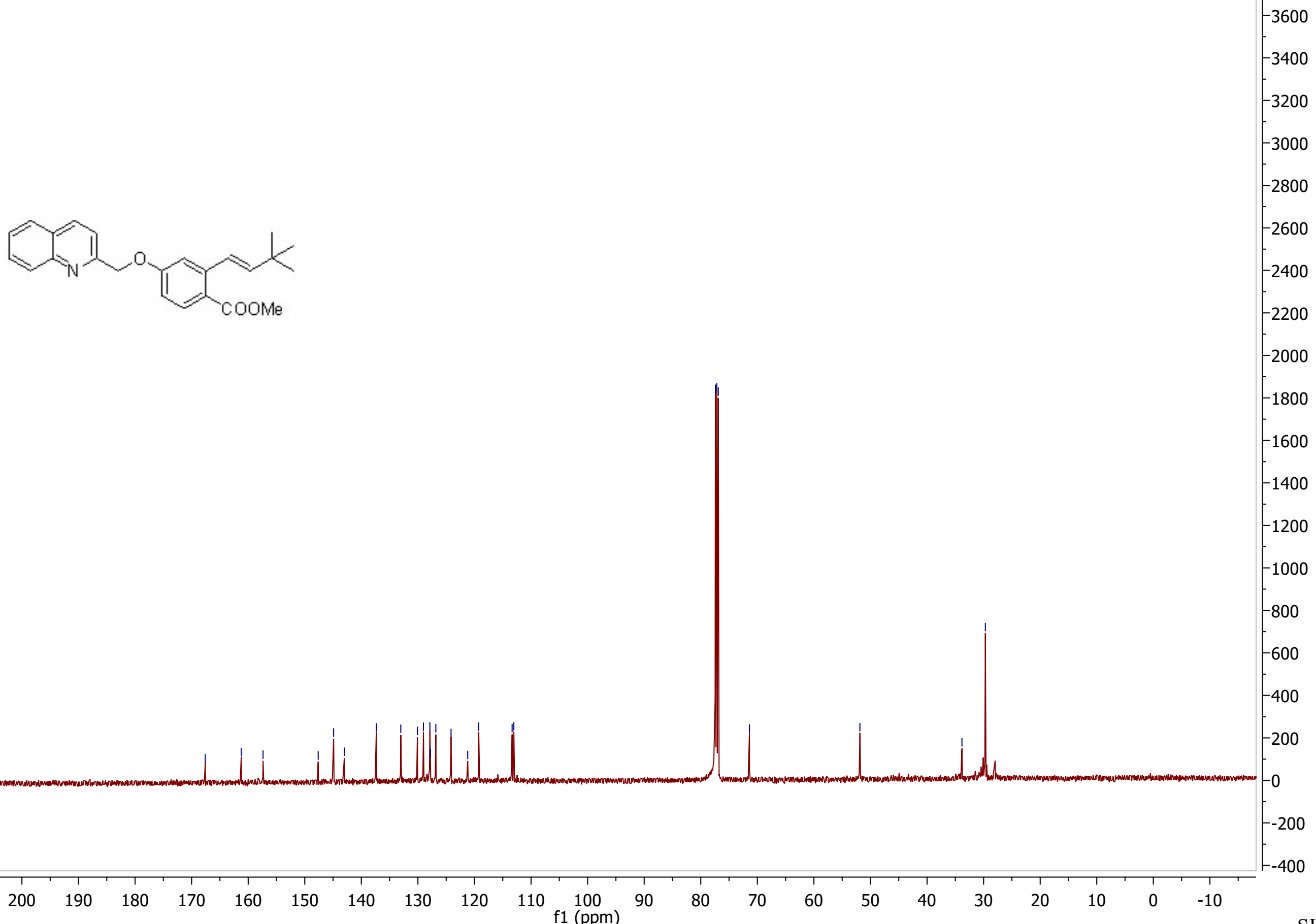